\title{
The Translator's Subjectivity in Aviation English Translation
}

\author{
Li Zhizhuo, Zhu Min, Zhou Yali \\ Civil Aviation Flight University of China, Guanghan, PR China
}

\section{Email address:}

jiaoyao76@163.com (Li Zhizhuo)

\section{To cite this article:}

Li Zhizhuo, Zhu Min, Zhou Yali. The Translator's Subjectivity in Aviation English Translation. International Journal of Applied Linguistics and Translation. Vol. 4, No. 3, 2018, pp. 46-51. doi: 10.11648/j.ijalt.20180403.11

Received: September 2, 2018; Accepted: October 19, 2018; Published: November 13, 2018

\begin{abstract}
This paper focuses on the translator's subjectivity in aviation English translation. Translator's subjectivity has been discussed a lot in literature translation rather than technical text translation. Aviation technical documentations are written in Simplified Technical English (STE) or controlled language to improve comprehension and translatability of this technical documentation. Due to the distinctive linguistic features such as high specialization, abundant terminology, complex sentence structure in aviation English, the objective of this study is to reveal to what extent the translator's subjectivity could be played in the aviation English translation process. Under the principle of "accuracy, conciseness, and conforming to codes of practice" in aviation English translation, the translator's subjectivity plays a significant role such as an accurate convey of the author's intention and an error correcting to the original text. The paper attempts to use a comparative method to analyze different translation versions taken from some aircraft operation and maintenance manuals to discuss on the translator's subjectivity in aviation English translation process. A comparative analysis of the faulty maintenance translation versions was studied to address the impact of the translator's subjectivity in the translation process.
\end{abstract}

Keywords: Translator's Subjectivity, Aviation English Translation, Error Correcting to Original Text, Controlled Language

\section{Introduction}

"Translation is a cultural fact that means necessarily cross-cultural communication because translation enables language to cross borders and helps intercultural exchange and understanding (Munoz-Calvo and Buesa-Gomea, 2010). [1]" "Translation ability stands for an essential component of linguistic and professional competence and allows a future expert to comprehend professionally important in formation in a foreign language, and to produce a translation in the target language. [2]" "Translators are agents of social transformation, who use their special discursive skills to bridge between cultures, re-create an aesthetic project, or disseminate and produce knowledge. They are regarded as gate-keepers and knowledge brokers, who have the power for reinforcing or modifying cultural representations (Castro, 2012). [3]" How close can any translation come to the original text or statement? Nida (2010) notes that "since no two languages are identical either in meanings given to corresponding symbols, or in ways in which such symbols are arranged in phrases and sentences, it stands to reason that there can be no absolute correspondence between languages no fully exact translation the impact may be reasonably close to the original but no identity in detail (Nida, 1964). [4]" Therefore, the process of translation must involve a certain degree of interpretation on the part of the translator. The PACTE research group (Beeby et al., 2003, p. 57-59) defines translation competence as "the ability to carry out the transfer process from the source text to the production of the target text in the function of the receptor's needs and the purpose of the translation. [5]" The translator's subjectivity refers to the creativity and imagination presented in the translation process, and it reflects to what an extent the translator could have his/her subjective initiative. Professor Zha Miangjian, said, "The translator's self-conscious cultural awareness, humanistic spirit and aesthetic creation construct the essential feature of the translator's subjectivity. [6]" In terms of the translator's subjectivity, after a comparison between the literature language and the science and technology language features, the previous scholars would always stress the translator's subjectivity in literature translation. However, just as scholars Li, Haijun \& Jiang, Xiaoyang put "Every kind of translation is an advanced and sophisticated mental activity and thus present to the translator enough space to develop his subjectivity. Even in the science and technology translation, the translator 
is supposed to fully develop his subjectivity. And in the process of science and technology translation, the fully developed the translator's subjectivity could help to correct the errors and exclude the ambiguity in the original text and make the translation an aesthetic one. [7]" Based on a deeply analysis of the aviation English language features, this paper intends to discuss the translator's subjectivity in aviation English translation process under the three principles of accuracy, conciseness, and conforming to codes of practice.

\section{Linguistic Features of Aviation English and Its Translation Techniques}

In terms of the lexical characteristics, there are many phraseologies, terminologies, abbreviations, and neologisms in aviation English. As for the syntactic features, complex sentences, long sentences, inverted sentences, elliptical sentences, and split sentences are frequently use in aviation English.

Textually speaking, cohesion and coherence are also used a lot, and there is even a unique writing rule in aviation English. Therefore, the aviation English translation process is not just a simple shift between words, and it requires the translator to fully develop his subjectivity to standardize the translation process. And if necessary, an aviation English translation specification manual should be established.

\subsection{Lexical Features in Aviation English and the Translation Technique}

\subsubsection{Phraseology and Terminology}

A distinct feature in aviation English is that many phraseologies and terminologies are used and most of the words comply with the principle of one word, one meaning. Due to the disparate development in aviation field and a lack of standard specification for phraseology and terminology, there are many synonyms and polysemy in aviation English. This always brings obstacles in the translation process. For example, these words: apron/ramp/parking stand/bay/tarmac/cul de sac denote similarly while differently.

Parking stand, parking bay and parking gate may have the same meaning, but some airports use parking gate to indicate the place that an aircraft parks while the nose-in position and connected with the pier or a gangway. While parking area and apron refers to the same place near the terminal building. Ramp refers to the access where only the maintenance technicians and pilots could approach the aircraft and just as parking area/ stand/ gate/ bay. Tarmac is a general terminology and it refers to all the hard surface or the asphalt surface, as the apron and the taxiway. Cul de sac is particularly use in Heathrow Airport to indicate the apron.

As for the aviation English words, the same words sometimes may have a different meaning. For example, Gear: Landing gear（起落架）, gear box（齿轮箱）, Generator: oxygen generator（氧气发生器）, AC generator（交流发电 机).

The meaning for some words in general English could be quite different from its meaning in aviation English context. Confusion of these words may result in significant catastrophe. Take hold as an example, in aviation English context, meaning stop the proceeding action or wait in the holding pattern; while in general English, hold could have the meaning of continue the proceeding action. An aircraft was rolling for takeoff, in the meaning time, the controller requested another aircraft who had got the landing clearance to go around. The captain required the first officer to ask whether they could continue the landing, "Can we hold, ask him if we can hold" he actually used hold to indicate the landing request. After inquiry of the rolling aircraft, "if you can just go ahead and hold", in this inquiry, hold means wait but the controller gave an inconsistent instruction to authorize the aircraft to go on with the takeoff process. And the landing aircraft once again requested the landing clearance, due to the rolling aircraft aborted the takeoff and it was too late to retract the landing gears and go around, at last the landing aircraft landed on the runway with the gears up! The aircraft was badly damaged after a fire and 34 persons on board were seriously injured!

The usage of wording in aviation English comply with the principle of accuracy, conciseness and unambiguity. When translated into Chines, this principle should also be complied with.

\subsubsection{Abbreviation}

Abbreviation refers to the shortened form of a word or phrase by usually shortening something or omitting parts of the word or phrase. There are many abbreviations in aviation English with the following categories.

(1) Initialisms and acronyms

Initialisms refers to an abbreviation consisting of the first letter or letters of words in a phrase (for example, VOR: Very High-frequency Omni-directional Range, VSI: vertical speed indicator), syllables or components of a word (TNT for trinitrotoluene), or a combination of words and syllables (PAPI: precision-approach path indicator). While acronyms refers to a word or name formed as an abbreviation from the initial components in a phrase or a word, usually individual letters (as in Radar: radio detecting and ranging, Sonar: sound navigation and ranging).

Sometimes the same acronyms may have different meanings. For example, ACS: aircraft communication system, ACS: aircraft control system and ACS: air-conditioning system. In this situation, the translator should make sure the acronym have the accurate meaning in the context.

(2) Blends or Portmanteaus

A portmanteau or portmanteau word is a linguistic blend of words, in which parts of multiple words or their phones are combined into a new word. As in avionics, coined by blending aviation electronics. Other examples such as: transceiver: transmitter receiver and heliport: helicopter airport.

\section{(3) Clippings}

Clippings refers to the formation of a new word by shortening it. For example, plane: airplane, copter: helicopter, a/ c: aircraft, B/ D: bearing and distance, C/M: control and monitoring, Rwy: runway, etc. 
According to the ATA specification i2200, as for the abbreviations, there is no need for the translator to coin an abbreviation. In the translation process, when an abbreviation appears for the first time, the full form should be provided. If no abbreviation form could be found in the dictionary, the translator should check the full form in the original text and translate the whole phrase and then provide an abbreviation for it.

\subsubsection{Protologism}

Protologism (newly-coined words) is a term invented in the early 2000s by Mikhail Epstein, an American literary theorist to refer to a new word which has not gained wide acceptance in the language. Newly-coined words reflect the development of modern aeronautical technology for the linguistic aspect. Acronyms, portmanteau words, clippings, compound words, derivative words, and loanwords are all newly-coined words, such as multi-mode-auto tracking (多模自动跟踪) and RADALT（雷达高度表）。

As for the translation of these newly-coined words, the translator should use the internet searching function thoroughly to check up its definition or context in the original text and fully understand its reference and connotation before the accurate translation.

\subsection{Syntactic Features of Aviation English and the Translation Technique}

\subsubsection{Complex Sentence and Long Sentence}

Complex and long sentences make another distinctive feature in aviation English. These sentences have complicated structure and many modifiers. Generally speaking, the long sentences in aviation English are featured with: 1) many modifiers; 2) many conjuncts; 3) many linguistic structure layers.

The long sentence in aviation English usually contains one instruction. There are two techniques to deal with the translation for these long sentences. One is by using conjunctions such as at the same time, yet, if, similarly etc. to split these long sentences and in the meantime, use pronouns like these, this, they etc. or use some nouns to act as the subject of the short sentences. By this way, the long sentences are separated into some short clauses and each clause just contain one topic. As for the complicated text indicating more than two complex actions or relations, the translator could develop his subjectivity, and use the parallel structure in the translation process on the basis of a thorough analysis of the original structure, a clear understanding of the relations among the modifiers and a full understanding of the original meaning. The parallel structure could make the translation version more concise. And visual marks such as dashes, letters and numbers are suggested to indicate the numeral order.

Example: The dossier must contain each of the following: a completed form REC-1, a three-view drawing of the aircraft, a photograph of the aircraft, a statement of the support data.

Translated version: 档案必须包含:

一份完整格式 REC-1

一份飞机三面视图
一份飞机照片

一份提供数据声明

The translator use the parallel structure in his translation process. Paratactic structure clearly and simply relays the original meaning and in the meantime makes the reading a simple and effortless experience.

\subsubsection{Passive Sentence}

Many passive sentences exist in aviation English to describe an objectivity and emphasize the action status and thus the subject of the action could be neglected. The subject of the action here could be whatever a person or no subject could be found here or even no subject at all.

In Chinese, passive sentences are seldom used and hence the translator should try to use active sentences in his translation. This could be another aspect he could develop his subjectivity in his translation. There are five techniques to change a passive sentence into an active sentence in aviation English translation process.

(1) If subject of the action could be found out, then the actor could be placed in front of the sentence to be the subject. The subject must be a noun to proceed the action in the sentence.

Example: The circuits are connected by a switch relay.

译文: 转换继电器连接电路。

(2) Change the infinitive phrase into the active verbs.

Example: These values are used by the commuter to calculate the altitude.

译文: 计算机通过这些数值来计算高度。

In the above examples, by changing the infinitive phrase to calculate into the active verb of the original actor, the translator changed the original sentence into an active sentence.

(3) In the procedure description, change the verb into the imperative sentence.

Example: The test can be continued by the operator. 译文:（操作者）持续测验。

(4) If no actor (the person or subject of the action) could be found, in the translation process, the translator could use pronouns like you, we etc. to be the subject of the active sentence.

Example: On the ground, the valve can be opened with the override handle.

译文: 在地面, 你可以用超控手柄打开阀门。

(5) Use Non-Subject Sentence.

If no actor could be found in the original sentence, and in the meantime in the translation process, it's difficulty or unnecessary to supplement the subject. In this situation, we could use non-subject sentence or we could just omit the subject.

Example: After reverse thrust is initiated, a full stop landing must be made.

译文: 反推手柄移动后, 必须进行全停着陆。

\subsubsection{Imperative Sentence}

In order to denote for instructing, ordering, warning, requesting or advising the listener to do (or not to do) 
something, imperative sentences are frequently used in aviation English. They are often used for giving instructions as to how to perform a task.

Example: Use the information on the new Revision Record and List of Effective Pages to verify the operations manual content.

译文: 新的修改记录和有效页面上的信息将用于核实使 用手册的内容。

\subsubsection{Inversion, Elliptical Construction and Dissever Sentence}

There are also elliptical constructions in aviation English, which is the omission from a clause of one or more words that are still understood in the context of the remaining elements. While inversion refers to the expressions in a sentence switch their order of appearance, that is, they invert. This kind of switch could make the sentence seem more compactness. And the dissever sentence could make the structure more balanced. In order to achieve the rhetorical effect, the author in aviation English always choose to use inversion, ellipsis and deserver sentences a lot in their writing.

Example: As the one primarily responsible for the airworthiness of the airplane, the owner or operator should select only qualified personnel to maintain the airplane.

译文: 为保证飞机的适航性, 飞机的执管者和使用者应 选用有资格的人员维护飞机。

Analysis: the original translation neglected that in the clause as the one primarily responsible for the airworthiness of the airplane actually the subject the owner or operator was omitted. In the original translation version, the translator did not realize this and thus in his translation, a misunderstanding was caused.

改译: 飞机的所有人或经营人是飞机适航性的首要责任 人，应该选择有资质的人员维护飞机。

\subsection{Three Principles Guiding the Aviation English Translation Process}

Accuracy, conciseness, and conforming to codes of practice constitute the three guiding principles in the aviation English translation process.

\subsubsection{Accuracy Principle}

Namely, accuracy refers to, 1) an accurate understanding of the original text without mistakes; 2) an accurate in the translation without ambiguity. Accuracy is the main principle in any kind of translation process. Hence, literal translation is often used in aviation English translation process, to avoid any distorted understanding or loss of information in the original text. Sometimes a back translation is suggested to test the accuracy of the translated text. By a comparison of the back-translation with the original text, the translator could check the accuracy of his original translation.

Example: For procedures that require fuel, fire equipment must be available.

译文: 加油及灭火设备应可用。

Analysis: In the original text, there is a definite requirement for the fire equipment, due to the translator's misunderstanding, the translated version didn't reflect this requirement.

改译: 需使用燃油的程序, 必须配备灭火设备。

Accuracy also means to use professional expressions, phraseology and terminology etc. instead of plain English. There are many ways of word-formation in aviation English, even simple words in general English may have quite different meanings. So in the translation process, the translator should try to use professional expressions a lot in the translation.

Example: Clear ice on the static ports can be difficult to detect.

译文: 静压孔上洁净的冰很难发现。

Analysis: Clear ice in meteorology refers to hard and crystal icy layers, always in the front of the wings, propellers and other parts.

改译：静压孔上的明冰很难发现。

Many translation inaccuracies do exist in present aviation English translations, especially in phraseology and terminology aspects duo to a lack of guiding principle for the standardized and normalized translation of glossary and terminology

\subsubsection{Conciseness Principle}

Conciseness principle means the translation should be as short and clear as possible. The aviation manuals and technical publications are written under the FAA Writing Standard and ASD-STE etc. rules, and thus the translation should also refer to those writing rules and use simple and concise language, eliminate the usage of variants of words, use the corresponding translation in the translation database. Zero translation could be used in the glossary and terminology.

Example: Pilots are authorized to deviate from their current ATC clearance to the extent necessary to comply with a TCAS II resolution advisory (RA).

译文: 飞行员有权偏离 ATC 的许可, 在必要的范围内 按 TCAS II 的 RA 指令去做。

Analysis: ATC is short for air traffic control and TCAS is short for Traffic Alert and Collision Avoidance System, RA for resolution advisory in the original text. These abbreviations are in the aviation manuals. A zero translation technique was adopted in the above sentence to make the translation seem more concise and clear.

To make a complete sentence structure, subjects or other subordinating conjunctions or clauses are needed in English. While Chinese is a kind of semantically paratactic language, with no possible confusion, grammatical or syntactic form could be omitted so as to achieve a more concise translation result.

Example: Use caution to prevent unwanted objects from hitting the airplane during towing and at all times when the airplane is not in service.

译文：拖行飞机与任何时候不使用飞机时，用告示牌防 止外物撞击。

Analysis: In the original text, at all times as a subordinating clause could be omitted in the translation.

改译: 在拖行或飞机不使用期间, 注意防止有害物体撞 击飞机。 


\subsubsection{Conforming to Codes of Practice}

Conforming to codes of practice refers to the translation of aviation English should following the writing rules of the aviation manuals and technical publications, including the language specification and the codes of practice in the field. A specific translation technique manual is suggested to standardize the layout, pattern, script, chart, sign, serial number and the wording etc. of the translation. The translation should be the same with the original text in the layout, writing style, terminology, chart and even the serial number of the pages.

Example: Bleed air is not available for nacelle anti-ice operation when the pressure regulating valve (PRV) has been closed due to a bleed air overheat, HP bleed valve failed open, or if the start valve is not closed.

译文: 由于引气过热, HP 引气活门关不上或如起动活 门未关闭而压力调节活门(PRV)已关闭时, 引气不可用于 发动机吊舱防冰。

Analysis: This translation directly used the original sentence structure, and caused the reader confusion to understand the text. A better way to avoid this is to abandon the original structure, reorganize the clauses and find out the causal relationship, and rewrite the translation.

改译: 由于引气过热, 高压引气活门没打开, 或起动活 门未关闭, 从导致压力调节活门 (PRV) 关闭, 则引气不 可用于发动机吊舱防冰。

\section{The Role of Translator's Subjectivity Plays in Aviation English Translation}

\subsection{Accurate Rendering of the Original Text}

As previously discussed, there is no emotional color in the writing of the aviation language, and standard and specification are given particular emphasis on and no personal style is needed. Yet this is not to say, the author has no choice of the wording in his writing process. In contrary, to clearly convey some procedures, the author may choose some vivid words in his writing. Therefore, in the translation process, according to Li, Yashu "the translator should fully understand the author including his intention, emphasis, even mood and tone. Only by achieving this, the translation might leave to the reader the same impression just as the original text. [8]"

Example: The entry method used (parallel, teardrop, or direct) is determined by the airplane track, not heading or direction from which the active route approaches the holding pattern.

译文: 进入等待的方法 (平行进入、修正角进入或直接 进入) 由飞机航迹确定, 而不是由接近等待航线的现用航 路航向或方位确定。

As professor Huang, Zhonglian said, "In technical translation, if once just mistakenly thought that only literal translation is permitted, then a terrible mistake would occur. [9]" In the original text, the author used the word teardrop to indicate the maneuver the aircraft entered the holding pattern, or track like this $\longrightarrow$. In this case, if the translator literally translates this teardrop into Chinese, the readers would have no idea of what the translator want to express. In contrary, the translator fully develops his subjectivity and creatively abandon the image of teardrop in his translation and fully understand that the maneuver that the aircraft enters the pattern was just like a teardrop, after correcting the entering angle. Thus the translator translated the teardrop into 修正角, to avoid the possible confusion.

\subsection{Error Correcting to the Original Text}

English linguist J. R. Firth once pointed out, "Each word when used in a new context is a new word." Therefore, in the translation process, the translator must have a strong contextual awareness in understanding and choosing the accurate meaning rather than just check the word in the dictionary for its isolate meaning.

There are many polysemous words in aviation English. Professor Li, Haijun said, "Ambiguity caused by polysemy is the stumbling block for technical translators to accurately understand the original text. In order to accurately understand the author and eliminate the ambiguity, the translator should remove this stumbling block prior to the translation process. Fully use the translator's subjectivity and logical thinking can help to eliminate the ambiguity. [7]" Take the word clear as an example, in aviation English, it has meanings like“清除”、“许 可”、“净空”、“晴空” etc. The translator should consider the context and if necessary, ask the professionals for help to eliminate the ambiguity and choose the appropriate meaning.

Example: The secondary engine parameters can be cleared by pushing the Secondary Engine Display switch. (动词)

译: 按压次要发动机显示电门可清除次要发动机参数。

Example: All test messages clear when the test switch is released. (动词)

译：松开测试电门将清除所有信息。

Example: Cleared for takeoff. (动词)

译: 可以起飞。

Example: Clear air turbulence can not be sensed by radar. (形容词)

译: 雷达感应不到睛空颠簸。

Example: Clear ice on the static ports can be difficult to detect. (形容词)

译: 静压孔上的明冰很难发现。

Example: This may cause an ice buildup which disturbs airflow over the static ports resulting in erroneous airspeed and altimeter readings, even when static ports appear to be clear. (形容词)

译：即使静压孔看似通畅，这也会造成冰的积聚，干扰 静压孔上方的气流流动, 从而导致空速和高度表产生错误 的读数。

Example: Be aware of wing clearance, engine clearance, and the possibility of FOD ingestion on the side of the airplane. (名词形式)

译: 注意机翼净空, 发动机净空, 和飞机外侧吸入外来 物损坏的可能性。

\section{Conclusions}

To sum it up, the translator's subjectivity is not only decided 
by the genre of the original text. House (2015) reviews the possible linguistic and social evaluations of translations and describes overt and covert translation types. In the latter case, "the translator must attempt to re-create an equivalent speech event. [10]" And literal translation is not the only way to translation the aviation English. The translator should take the differences between English and Chinese in terms of words, sentences and semantic field into consideration in the translation process to achieve an accurate and concise translation results.

\section{References}

[1] Munoz-Calvo \& Buesa-Gomez. (2010), Translation and Cultural Identity: Cambridge Scholars Publishing.

[2] Ekaterina Tarasova \& Anna Kradetskaya, (2015). The Role of Motivation in Technical Translation Teaching to Master Degree Students. Procedia-Social and Behavioral Science 206 (2015)189-192.

[3] Castro, N. (2012), Translation: A Meeting Point for Interdisciplinary Enquiry, Global Media Journal-Canadian Edition, Vol. 5.
[4] Nida, E. (1964), Principles of Correspondence, In: Venuti, L. (ed.), the Translation Studies Reader, Routledge, London.

[5] PACTE GROUP [A. Beeby, M. Fernández Rodríguez, O. Fox, A. Hurtado Albir, W. Neunzig, M. Orozco, M. Presas, P. Rodríguez Inés, L. Romero (Principal investigator: Amparo Hurtado Albir)] (2003). Building a Translation Competence Model In: Alves, F. (ed.). Triangulating Translation: Perspectives in Process Oriented Research (pp. 43-68). Amsterdam: John Benjamins.

[6] Zha, Mingjian, \&Tian, Yu. (2003). Discussion on the translator's subjectivity- A discussion from the marginalization of the translator's cultural position. Chinese Translators Journal, 45-47.

[7] Li, Haijun \& Jiang, Xiaoyang. (2012). Translator's subjectivity in science and technology translation. Chinese Science \& Technology Translators Journal, 42-44.

[8] Li, Yashu. (2007) Science and technical translation study, 57.

[9] Huang, Zhonglian. (2007) Science translation, 107.

[10] House, J. (2015). Translation quality assessment. Past and present. New York: Routledge. 